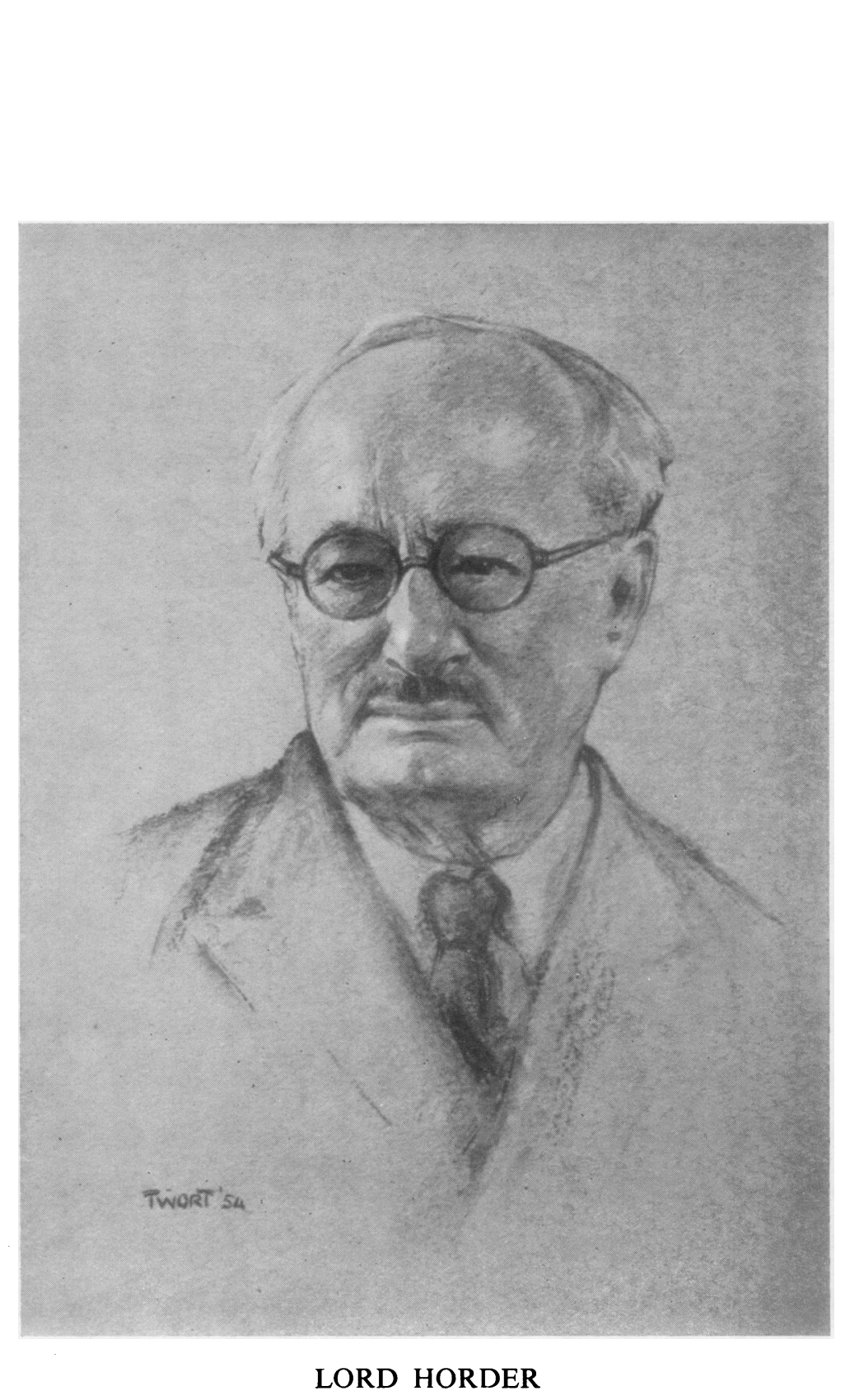

[ facing p. 225 


\section{LORD HORDER}

Lord Horder died on August 13, 1955, at the age of 84 . He was the senior member of the Editorial Board of the Annals, and had been chairman of the Empire Rheumatism Council from its foundation in 1936 until his retirement in 1953. He had also been President of the Heberden Society. Although he was the greatest British clinician of his time and had lived through a period of revolutionary change in the science of medicine and in the organization of its services to the public, his amazing and undimmed mental and physical energy made him completely master of the rapidly changing scene. The incidence of rheumatism-at a time when this disease group was hardly a respectable field of study-was a major concern of his, and his period of chairmanship of the Empire Rheumatism Council did much to dispel the profound apathy which prevailed, both in the medical profession and among the lay public in Great Britain.

He will be much missed in the international field of rheumatology. Few men can have lived a life so long, so full of service right to its sudden end.

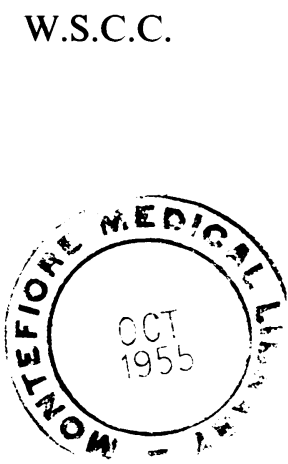

